\title{
O tabu da censura: análise de uma campanha para que você Não se engane sobre a classificação indicativa
}

Ivan Paganotti ${ }^{1}$

1 Doutorando em Ciências da Comunicação pela Escola de Comunicações e Artes da Universidade de São Paulo (ECA-USP), com bolsa Capes, sob orientação da Profa. Dra. Mayra Rodrigues Gomes. É membro do Núcleo de Pesquisas em Comunicação e Censura (NPCC-USP) e do grupo de estudos Midiato/ECA-USP. ivanpaganotti@gmail.com 


\section{Resumo}

Enquanto o Supremo Tribunal Federal não decide sobre a constitucionalidade dos fundamentos legais que permitem a cobrança de multas e outras punições contra as empresas que desrespeitam a classificação indicativa, o Ministério da Justiça promoveu a campanha publicitária Não se engane, para defender esse controle prévio audiovisual. Este artigo avalia a estratégia adotada por essa campanha, baseada na pressuposta mimetização por parte das crianças de comportamentos violentos, sensuais ou abusivos presentes na mídia. Com isso, é possível refletir sobre a disputa entre diferentes instâncias (audiência, mídia, judiciário, executivo, ONGs) que concorrem para definir o sentido de práticas comunicativas adequadas.

\section{Palavras-chave}

Comunicação, liberdade de expressão, censura, classificação indicativa, propaganda.

\section{Abstract}

The Brazilian Supreme Federal Court has been questioning the constitutionality of the legal grounds used to justify fines charged against broadcast companies which may not respect media ratings. While this decision is not made, the Ministry of Justice has promoted an advertising campaign called Don't be mistaken, defending this audiovisual previous control. This article evaluates the strategy adopted by this campaign, based on the assumption that children may mimic violent, sexual or abusive behaviors shown by the media. Considering this, it is possible to reflect on the dispute between different stances (audience, media, NGOs, the judiciary and the executive power) which fight to define the meaning of adequate communicative practices.

\section{Keywords}

Communication, free speech, censorship, media rating, propaganda. 


\section{Introdução}

A classificação indicativa passou a sofrer o mesmo escrutínio que impõe sobre as obras audiovisuais que pretende avaliar: não está bem definido se a classificação seria somente uma indicação, como sugere seu próprio nome, ou se a imposição de punições como multas poderia envolver um retorno de práticas de censura travestidas sobre o manto do Estado de direito democrático. O mecanismo da classificação indicativa é bastante claro e transparente, e sobre ele não restaria dúvida (MINISTÉRIO DA JUSTIÇA, 2006; 2012) - trata-se de uma decupagem sistemática de toda a produção audiovisual para avaliar sua adequação a diferentes públicos etários devido à presença de conteúdos considerados indevidos por tratarem de sexo, violência ou drogas. Porém, são seus princípios que foram colocados em cheque ao se questionar a fundamentação jurídica para a imposição de punições como multas. O problema principal emana do artigo 254 do Estatuto da Criança e do Adolescente (ECA), que impede emissoras de "transmitir, através de rádio ou televisão, espetáculo em horário diverso do autorizado ou sem aviso de sua classificação", o que pode levar a "multa de vinte a cem salários de referência"; em casos mais graves, seria possível inclusive "determinar a suspensão da programação da emissora por até dois dias".

O suspense sobre a questão é mantido desde o final de novembro de 2011, quando o ministro do Supremo Tribunal Federal Joaquim Barbosa interrompeu ${ }^{2}$ o julgamento da Ação Direta de Inconstitucionalidade de número 2404 ao pedir vistas nesse processo que considerava a legalidade das punições do sistema de classificação indicativa a partir da fundamentação desse artigo do $\mathrm{ECA}^{3}$. O julgamento foi interrompido logo depois que três de

2 Ver: "Suspenso julgamento sobre horário obrigatório para programas de rádio e TV". Notícias STF. Disponível em: http://www.stf.jus.br/portal/cms/verNoticiaDetalhe.asp?idConteudo=195122

3 O processo da ADI 2404 - incluindo o voto do relator, do ministro Dias Toffoli - está disponível em: http://www.stf jus.br/portal/processo/verProcessoAndamento.asp?numero=2404\&classe=ADI\&codigoClasse=0\&origem=JUR\&recurs $\mathrm{o}=0$ \& tipoJulgamento $=\mathrm{M}$ 
seus colegas - os ministros Luiz Fux, Cármen Lúcia Antunes Rocha e Ayres Britto - seguiram o voto do relator Dias Toffoli a favor da medida colocada em questão a pedido do Partido Trabalhista Brasileiro (PTB), acatando a tese de que as emissoras não podem ser punidas, pois a classificação deve ter somente caráter indicativo, como diz seu próprio nome:

(...) Há, sim, censura prévia, já revelada na necessidade de submissão da programação de rádio e de televisão à autoridade administrativa, a qual, por sua vez, não apenas exercerá a classificação indicativa, no sentido de informar a faixa etária e os horários aos quais "não se recomend[a]" (conforme prevê a Constituição), mas de impor e condicionar, prima facie, a veiculação da programação no horário autorizado, sob pena de incorrer em ilícito administrativo.

O que se faz, nesse caso, não é classificação indicativa, mas restrição prévia à liberdade de conformação das emissoras de rádio e de televisão, inclusive acompanhada de elemento repressor, de punição. $O$ que se diz é: "a programação ' $X$ ' não pode ser transmitida em horário diverso do autorizado pela autoridade administrativa, sob pena de pagamento de multa e até de suspensão temporária da programação da emissora no caso de reincidência". O que seria isso senão ato de proibição, acompanhado, ainda, da reprimenda? ${ }^{4}$

Enquanto esse artigo é escrito, em agosto de 2012, é difícil imaginar ainda o desfecho da questão - entretanto, é tentador imaginar que aos quatro votos já apresentados poderá se somar ao menos o voto do ministro Marco Aurélio, notório defensor da liberdade de expressão em outros casos de colisão de direitos (PRETZEL, 2008). Ao se aproximar da metade dos votos dos juízes, a ADI 2404 pode colocar em xeque o instrumento coercitivo que impõe a classificação indicativa. Obviamente, a classificação indicativa pode continuar mesmo sem a possibilidade de multar casos de descumprimento de suas indicações. Porém, a condenação simbólica do instrumento punitivo como censura, como tem sido classificada pelos ministros do STF no julgamento, pode enfraquecer a legitimidade desse processo ante os olhos do público.

4 TOFFOLI, Dias. "Ação Direta de Inconstitucionalidade 2.404 Distrito Federal - voto do relator", p. 30. Disponível em: http://www.stf.jus.br/arquivo/cms/noticiaNoticiaStf/anexo/ADI2404DT.pdf 
Em evidente reação ao impasse no STF e antevendo um possível revés à sua força coercitiva, o Ministério da Justiça procurou agir em duas esferas para reconstruir a legitimidade das práticas da sua classificação indicativa: nas salas de reunião, promoveu ou participou de eventos com organizações que representam formal ou informalmente o público para costurar e difundir apoio e sustentação para a classificação indicativa; simultaneamente, nas tribunas da imprensa, nas salas de cinema e na sala de estar dos brasileiros difundiu artigos e campanhas publicitárias para defender a importância da classificação e diferenciá-la da censura. A página principal do site do Ministério da Justiça ainda traz notícias sobre audiência pública que, metonimicamente, representaria o desejo da sociedade que "apoia multa por descumprimento de classificação indicativa", como é possível ver na Imagem 1 a seguir:

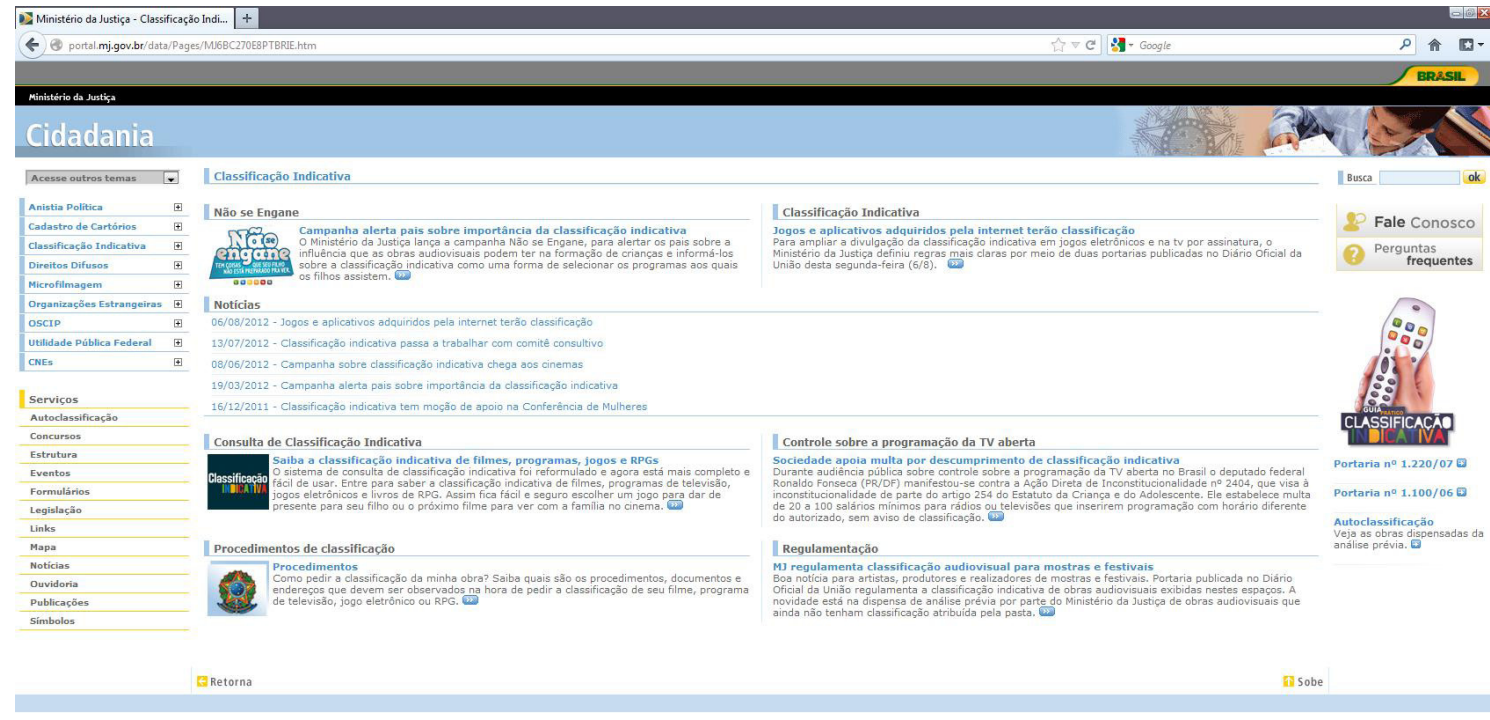

Imagem 1. Site do Ministério da Justiça sobre a Classificação Indicativa - captura de tela em 4 set. 2012. Disponível em: www.mj.gov.br/classificacao

Em artigos (CARDOZO; ABRÃO, 2012) ou entrevistas à imprensa, José Eduardo Cardozo, o ministro da Justiça, também procura reforçar sua interpretação sobre a constitucionalidade da classificação indicativa e sua diferença em relação às práticas de censura, eixo predominante na 
estratégia da campanha que o Ministério da Justiça (MJ) buscou orquestrar em resposta ao impasse no STF:

\begin{abstract}
As pessoas, às vezes, confundem conceitos. Uma coisa é a censura. É quando se impede alguém de apresentar um pensamento, apresentar um conteúdo de comunicação. É quando se corta, é quando se mutila uma situação em que a pessoa quer se comunicar. Outra coisa muito diferente é permitir a comunicação apenas indicando exatamente aquela faixa etária. Hoje, vivemos tempos de liberdade e é nesse contexto que temos que analisar a chamada classificação indicativa. (CARDOZO apud LIMA, 2012)
\end{abstract}

Ao indiretamente criticar a confusão de "pessoas" - entre as quais se implicariam os quatro ministros do STF citados anteriormente - que não saberiam diferenciar a "censura" que "corta", "mutila" ou que "impede alguém de apresentar um pensamento" da permissão "indicando" as faixas etárias adequadas, revela-se o cerne do caráter também "indicativo" da campanha promovida pelo MJ. Se o poder de sanção encontra-se nas mãos do STF - que pode proibir as punições em casos de desrespeito à classificação indicativa - o executivo esboça um recuo, para reorganizar seus reforços: não mais ameaçando com punições, mas fortalecendo seu caráter paternalista ao apontar não só o que é adequado para qual faixa etária, mas qual seria o sentido apropriado para termos como censura ou classificação indicativa.

Nessa disputa, diferentes instâncias (audiência, mídia, judiciário, executivo, ONGs) concorrem para definir o sentido de práticas adequadas: quais públicos podem ter acesso a quais conteúdos? Quem pode determinar o que é ou não adequado? Quem pode definir as regras do jogo - e as punições quando elas são rompidas? Como convencer o público - ou impor argumentos - em casos de divergência sobre quem pode decidir sobre a visibilidade de temas polêmicos?

Para tratar desses questionamentos, este artigo procura avaliar a estratégia adotada pelo Ministério da Justiça para conter os polêmicos sentidos atrelados 
ao termo ideologicamente carregado censura como uma suposta antípoda à terminologia classificação indicativa. Para isso, será avaliada a campanha publicitária Não se engane, difundida em 2012 como resposta à indefinição sobre a legitimidade da classificação indicativa, fornecendo argumentos visuais ao público sobre a ameaça que os conteúdos midiáticos podem apresentar para a inocência das crianças - e, com isso, fortalecendo os argumentos sobre a necessidade prática da classificação indicativa para barrar esse perigoso contágio audiovisual com sexo, violência e drogas.

Essa estratégia pode não ser bem-sucedida em reverter (e, principalmente, por ignorar) a comparação de termos inicialmente colocada em questão - se a classificação indicativa envolveria uma ação inconstitucional, seja ela uma prática de censura ou não. Além dessa alteração de temas em disputa, é necessário também avaliar a troca de arena de combate sobre a definição da legalidade da classificação - questionada pelos juízes no Supremo Tribunal Federal - para o palco midiático público - focando a legitimidade dessa classificação como uma resposta a anseios coletivos de maiores restrições sobre o conteúdo audiovisual potencialmente inadequado ou como solução científica fundamentada em pesquisas e estudos sobre os efeitos deletérios da recepção dessas imagens.

Como hipótese inicial, esta pesquisa considera se a própria tática empregada pela campanha do Ministério da Justiça pode ser ela mesma classificada como inadequada, para não se dizer tardia ou de foco equivocado, por tratar de uma questão que parece fugir ao público: em um sentido, a questão não é decidida em um foro representativo como o legislativo, que pode sofrer mais diretamente a pressão popular; em outro sentido, a campanha aposta sobre a (ex)pressão popular justamente em uma questão que envolve colisões de interesse entre diferentes sentidos dessa própria liberdade de expressão. Ao sugerir uma pressão indireta da população (incentivada pelas campanhas publicitárias) contra os juízes que avaliam o caso, o Ministério da Justiça pode colocar em questão justamente o debate atual sobre o papel político do STF e tentar minar - ou fortalecer, caso sua causa seja atendida - a esperança 
depositada sobre a capacidade reformista dos ministros em interpretar (ou remendar) a constituição. Por outro lado, já se insinuaria um cenário de consumada inconstitucionalidade das punições, que a campanha parece prever o revés, apostando na pressão popular para a formação de novas táticas de pressão, dessa vez sobre as próprias emissoras, constrangidas a manter o modelo de classificação indicativa mesmo sem a penalidade financeira do poder público e suas multas ameaçadoras (e agora ameaçadas), mas em respeito à pressão da audiência - ou seja, do poder do público ${ }^{5}$.

\section{Negativos e remediações: o sentido do controle audiovisual}

Os "apagamentos e exclusões constituem as próprias operações da mise-en-scène" (LYOTARD, 2005, p. 224) cinematográfica, não só devido à composição de campo do enquadramento e a consequente exclusão do que fica fora de cena do quadro fílmico, mas também, em sentido mais amplo, pela definição das falas e gestos que não devem fazer parte da encenação ou da performance dos personagens, além dos cortes e outras estratégias de edição. Nesse sentido, não custa lembrar o próprio processo químico pelo qual o filme tradicional é revelado a partir de seu negativo - mas todas as mídias audiovisuais, digitais ou não, também passam por esse mesmo processo de recorte de campo e de edição de possibilidades. Desse mecanismo de definição pela interdição decorre o conceito de "normalização libidinal" de Lyotard (2005, p. 226), uma "exclusão de tudo que, em cena, não pode ser aplicado ao corpo do filme e, fora de cena, ao corpo social".

Com isso, metonimicamente o filme representaria, como limite de possibilidades latentes, os interditos sociais e constrangimentos coletivamente

$5 \quad$ Além dos objetivos discutidos nos parágrafos anteriores, esta pesquisa também pretende relacionar os autores discutidos nos outros artigos apresentados nesse dossiê, resultado dos encontros promovidos pelo Grupo de Estudos de Linguagem: Práticas Midiáticas (Midiato-ECA-USP) durante os Seminários Linguagem e Práticas Midiáticas, realizados na ECA-USP no segundo semestre de 2011. Logicamente, não se pretende sugerir uma síntese de obras tão diversas. O que se busca é esboçar algumas linhas de convergência entre a riqueza de conceitos propostos por esses autores (que será tratado na segunda parte desse trabalho, a seguir) e uma possível aplicação dessas reflexões na análise de um caso específico (foco da terceira parte desse artigo). 
compartilhados e reverenciados - mesmo quando um filme pretende encenar sua transversão acaba por, indiretamente, reforçar os tabus, reconhecidos na tela, propondo a "resolução de uma dissonância" (LYOTARD 2005, p. 224), seja no tradicional final feliz com a punição dos transgressores, ou na oferta trágica de choque catártico ao público, apresentando o crime sem punição, o acaso absurdo ou ao frustrar a expectativa de recompensa dos heróis. Dessa forma, a experiência estética serve à política, tratando "do que se vê e do que se pode dizer sobre o que é visto, de quem tem competência para ver e qualidade para dizer" (RANCIÉRE, 2005, p. 17).

Por tratar desses complexos regimes de visibilidade, a película fílmica traduz as tensões sociais de forma privilegiada: é arena de disputa por apresentar não só o espaço de representação do visível, mas também por propor "diferentes formas de apropriação dos mecanismos de produção da representação" (HAMBURGER, 2005, p. 208), potencializados não somente por o que pode ser dado a se ver, mas por quem poderá definir o campo do visível, as abordagens legítimas e as vozes que devem ser ouvidas. Nesse sentido se insere também o debate próprio aos bastidores das produções audiovisuais sobre a adequação de determinados conteúdos a audiências que demandariam proteção - como crianças e adolescentes. Esse fator é determinante na composição de um filme, novela, videogame ou programa televisivo, pois o recorte desses conteúdos definirá, de forma inversa, o corte do público: quanto mais ampla a temática e mais aberta a questões polêmicas, maiores serão as fatias do público que deixariam de ser contabilizadas como audiência potencial por restrições impostas (como as faixas de horário televisivo, correlacionadas com a classificação indicativa para o público que teoricamente acessaria aquela mídia naquele momento) ou voluntárias (pela restrição de pais ou pelo desejo do próprio público em evitar temáticas desconfortáveis).

Em meio a essa "disputa pelo controle da visualidade" (HAMBURGER, 2007, p. 114), a delimitação de quais temas merecem a invisibilidade foi alterada pela oferta de maior espaço midiático para conteúdos violentos 
e sexuais, relacionados ou não ao consumo de drogas - justamente as três temáticas que a classificação indicativa pretende reativamente conter (MINISTÉRIO DA JUSTIÇA, 2012, p. 8). Entre esses pontos de erupção de conflitos e desconforto, Esther Hamburger destaca justamente as representações midiáticas da violência como espaços liminares, "que resistem a ordenamentos e explicações, espaços privilegiados para a criação de sentido" (HAMBURGER, 2007, p.128). Assim, a violência que não pode ser contida socialmente também não poderia ser deixada de fora das mídias.

Seguindo essa mesma crítica da atração espetacular, Figueiredo (2010, p. 59) aponta que também na alta cultura e nas propostas de vanguarda predominaria uma estética do choque, devido à concepção difundida de que "a obra de valor é aquela que provoca escândalo e é rejeitada pelo grande público". Entretanto, como frisado pela autora, nesse caso os excessos não procurariam atrair audiência, mas possivelmente ofendê-la, repugnada pelo que é mostrado pela obra de arte que propõe um olhar original (mesmo que desagradável) sobre a cultura.

Tanto o espetáculo que oferece violência, sexo e drogas para atrair as massas sedentas por sangue e prazer quanto a arte repelida pelo público ao tratar dessas mesmas questões em abordagens viscerais apresentam um problema particular quando se trata da oferta desses conteúdos a públicos vulneráveis e em formação, como crianças e adolescentes. Citelli (2010) aponta que desde o começo do século XX já havia uma preocupação sobre efeitos potencialmente negativos na formação moral das audiências:

No plano interno dos Estados Unidos, tratava-se de preservar a saúde moral dos jovens, supostamente incapazes de separar o joio do trigo, impotentes para discriminar o certo e o errado, frágeis em seu aparelho perceptual, sugestionáveis e prontos para cometer os possíveis desatinos e transgressões eventualmente expostos pela ficção televisiva, noticiários e programas de humor. Vale dizer, a questão residia em circundar as novas gerações, vigiando os mediadores de imaginários, símbolos, representações, a fim de que não provocassem 
desvios de condutas, comportamentos, levando as audiências juvenis a assimilarem valores não condizentes àqueles preconizados pelo one way of life (CITELLI, 2010, p. 71).

Essa abordagem formativa - preocupada com a deformação moral ou visualizando os potenciais didáticos dos meios de comunicação de massa em promover educação remota em escala industrial - revela a preocupação com a necessidade de disciplinar a mídia: de um lado, seria necessário controlar o indesejado, contendo as manifestações de luxúria, ira e pecados afins; de outro, seria possível promover as condutas e saberes com o auxílio da linguagem e do alcance dos meios de comunicação que já atraiam as massas. Essas duas visões sobre educação nas mídias (evitar a deformação e promover a formação), White lembraria, ecoam justamente uma abordagem nietzschiana sobre o os sentidos da "disciplina", que se constitui a partir do que "proíbe os seus participantes de fazer" (WHITE, 2001, p. 142). Mais uma vez temos aqui o retrato em negativo do caminho a ser seguido a partir do reflexo da conduta condenada.

As duas abordagens também revelam uma preocupação considerável sobre os efeitos da mídia, e influenciam a forma como a classificação indicativa é promovida até hoje. Entretanto, se a avaliação estatal de produtos audiovisuais já conseguiu superar o juízo "indistinto" (que vê a qualidade pelo prisma do prazer proporcionado ao público) e o juízo "diacrítico" (que avalia o estilo artístico da obra, sua inserção no contexto social ou suas inovações estéticas), ela ainda apresenta uma leitura limitada - e limitadora - do juízo "axiomático" (que questionaria os efeitos das obras no pensamento), como proposto por Badiou (2002, p. 111). Essa perspectiva poderia ser classificada como deformadora do juízo axiomático, pois não contempla as potencialidades críticas da própria audiência - mesmo no caso de públicos ainda em formação, como jovens e crianças - em interpretar o que veem; ao contrário, só teme a absorção mimética de condutas indesejadas e o choque com conteúdos inadequados. 
Ao preocupar-se exclusivamente com as ameaças e riscos da exposição aos meios de comunicação, acabamos por ignorar um lado do rico debate sobre a "potencialidade" dos meios - o estudo dos potenciais de diferentes mídias, questionando como esses veículos podem alterar seus limites, seja por sua própria ação ou devido à ajuda ou conflito de outros meios, um dos focos nas análises de Ryan (2004, p. 35). Ao temer os efeitos nefastos, as fronteiras dos potenciais midiáticos acabam por sofrer mais limitações, que tolhem suas possibilidades de expansão e produção de novos sentidos.

Essa abordagem behaviorista, que teme e pretende controlar o contágio midiático, envolve uma pretensão de que os efeitos possam ser eles mesmos previstos. Como lembra Aumont (1993, p. 92), Eisenstein já registrava frustração ao tentar aplicar a "reflexologia pavloviana" para combinar estímulos que sugerissem respostas específicas de seu público: a cena final de $A$ greve era eficaz em chocar plateias de operários ao contrapor imagens de massacres da polícia czarista com cenas de abate de bois, mas perdia sua força para audiências rurais, indiferentes quanto à força de imagens violentas que eram parte de suas práticas cotidianas.

Cabe questionar se a análise dos reflexos e as respostas aos estímulos poderia envolver uma controversa leitura "imediata", na terminologia de Bolter e Grusin (2000). Os dois autores sistematizaram diferentes concepções históricas que sugeriam uma relação direta entre representação e objeto representado, confundindo ou enganando audiências que pretendiam acreditar ver, de forma transparente, uma realidade sem mediação (BOLTER; GRUSIN, 2000, p. 30) - e, talvez, sem crítica, interpretação, possibilidade de leituras desviantes ou respostas diversas. Poderíamos dizer que essa perspectiva "imediata" também envolveria o engano (ou o logro) dos que assumem uma relação direta entre a representação midiática e os esquemas mentais do 
público ou até as condutas das audiências? Bolter e Grusin mostram que a visão "imediata" não é a única, e que convive e retroalimenta seu oposto, focando a opacidade e a hipermediação, além da chamada "remediação" (BOLTER; GRUSIN, 2000, p. 45), ou seja, a representação de uma mídia em outra. Essa abordagem diferente se mostra mais rica para a análise proposta a seguir, justamente por discutir um caso específico em que a fronteira entre uma mídia (a TV) e seus efeitos (na audiência) é discutida por outras mídias (a propaganda e/ou o cinema). Essa visão retoma a preocupação de Ryan (2004, p. 35), mencionada anteriormente, de avaliar as influências de um meio sobre os limites de outro - ou, nas palavras de Bolter e Grusin, a "remediação como reforma", pois "nossa cultura vê um meio de comunicação como um reformador, podendo aprimorar outros meios" (2000, p. 59).

\section{Fantasia, contágio e mímica: uma análise da campanha Não se engane}

Entre os meios que poderiam reformar ou aprimorar os outros, a publicidade apresenta-se com papel destacado devido à sua pretensão de estimular condutas (de consumo ou de posicionamento político) ou formar opiniões (sobre a imagem de produtos, indivíduos, instituições ou sobre ideias abstratas) por meio da exposição midiática ao público. Lançada em março de 2012, poucos meses depois do impasse no STF sobre a inconstitucionalidade das punições impostas às emissoras que desrespeitarem a classificação, a campanha surpreende inicialmente pela adoção das imagens infantis em temas polêmicos, como é possível ver nas Imagens 2 a 4 : 

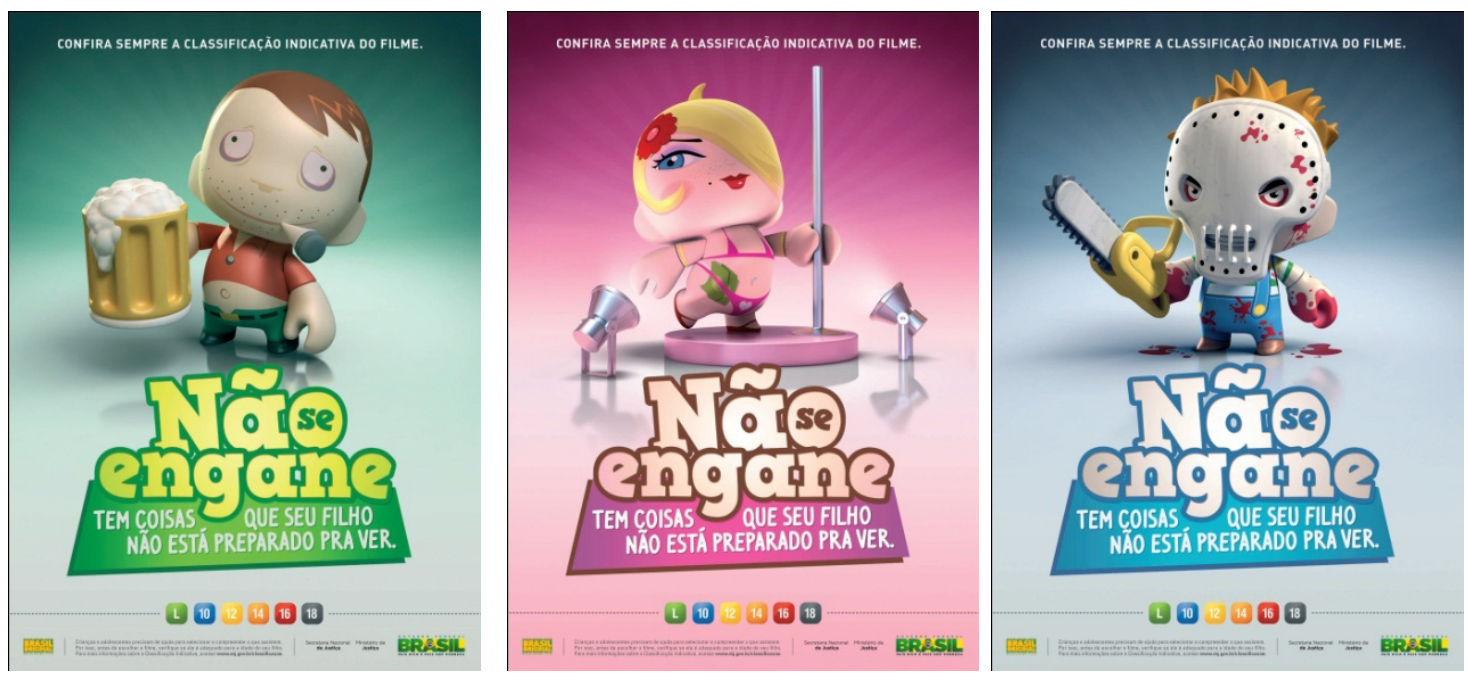

Imagens 2 a 4. Campanha Não se engane: tem coisas que seu filho não está preparado pra ver, do Ministério da Justiça?.

A campanha pretende chocar, inicialmente, pela dissonância entre o traço - característico de desenhos e brinquedos infantis - e sua temática sombria. Também incomoda por mostrar crianças em situações adultas e pretensamente desviantes: alcoolismo, comercialização da sexualidade e violência assassina. 0 texto na base dos cartazes afina o tom retórico da campanha:

Crianças e adolescentes precisam de ajuda para selecionar e compreender o que assistem. Por isso, antes de escolher o filme, verifique se ele é adequado para a idade do seu filho. Para mais informações sobre a Classificação Indicativa, acesse www.mj.gov.br/classificacao.

Uma primeira avaliação dessa campanha poderia sugerir, como apresentado na introdução deste artigo, que se trata de uma estratégia para motivar o público a pressionar pela continuidade da classificação indicativa, mesmo que essa pressão não consiga impedir os ministros do STF de considerar as punições impostas pelo Ministério da Justiça como inconstitucionais. Em nenhum momento essa propaganda retoma diretamente a diferença entre censura e classificação indicativa defendida pelo ministro José Eduardo Cardozo, 
como discutido anteriormente. Entretanto, no final do mesmo mês o ministro voltou à mídia em artigo para defender a classificação, reprisando o argumento de que não se trata de censura:

\begin{abstract}
Em nosso modelo, são as emissoras que se autoclassificam, segundo três conteúdos temáticos: drogas, violência e sexo. Os critérios se distanciam das subjetividades governamentais, pois são fixados previamente e construídos socialmente a partir de consultas públicas e estudos especializados sobre o comportamento das crianças e sua tendência de imitar aquilo que assistem. Um elemento estruturante da política é que, respeitada a gradação da faixa horária protetiva das $6 \mathrm{~h}$ às 23h, tudo pode ser exibido. A supervisão coercitiva do Estado é limitada e não admite censuras, vetos ou cortes de conteúdos, sejam prévios ou posteriores (CARDOZO; ABRÃO, 2012 - grifo nosso).
\end{abstract}

Fica claro, pelo cartaz, que a campanha implicitamente trata dessa distinção nublada e sob litígio entre os termos censura e classificação indicativa - é essa confusão que a campanha pretende evitar propondo que o público "Não se engane". Entretanto, o cartaz não deixa claro com o que o público poderia se enganar: a campanha se omite de defender um tema complexo, que demandaria justificativas discursivas, simplificando sua argumentação pelas imagens das três crianças travestidas e transviadas. A leitura dos cartazes somente propõe uma interpretação mais simples: o público não deve se enganar (formulação explícita), achando que as crianças podem ver violência, sexo e drogas sem se influenciarem e copiarem esse comportamento (sugestão implícita pelas imagens). A confusão censura/classificação indicativa só pode ser colocada em questão pelo acompanhamento paralelo do debate nos artigos e entrevistas na imprensa ou nas notícias sobre o STF.

Duas peças de vídeo também foram produzidas para serem veiculadas pela TV e cinema. Uma delas, intitulada Drogas (Imagens 5 a 9), evidencia o problema do comportamento mimético da criança vulnerável e exposta à ameaça midiática que explora os maus exemplos de conduta: 

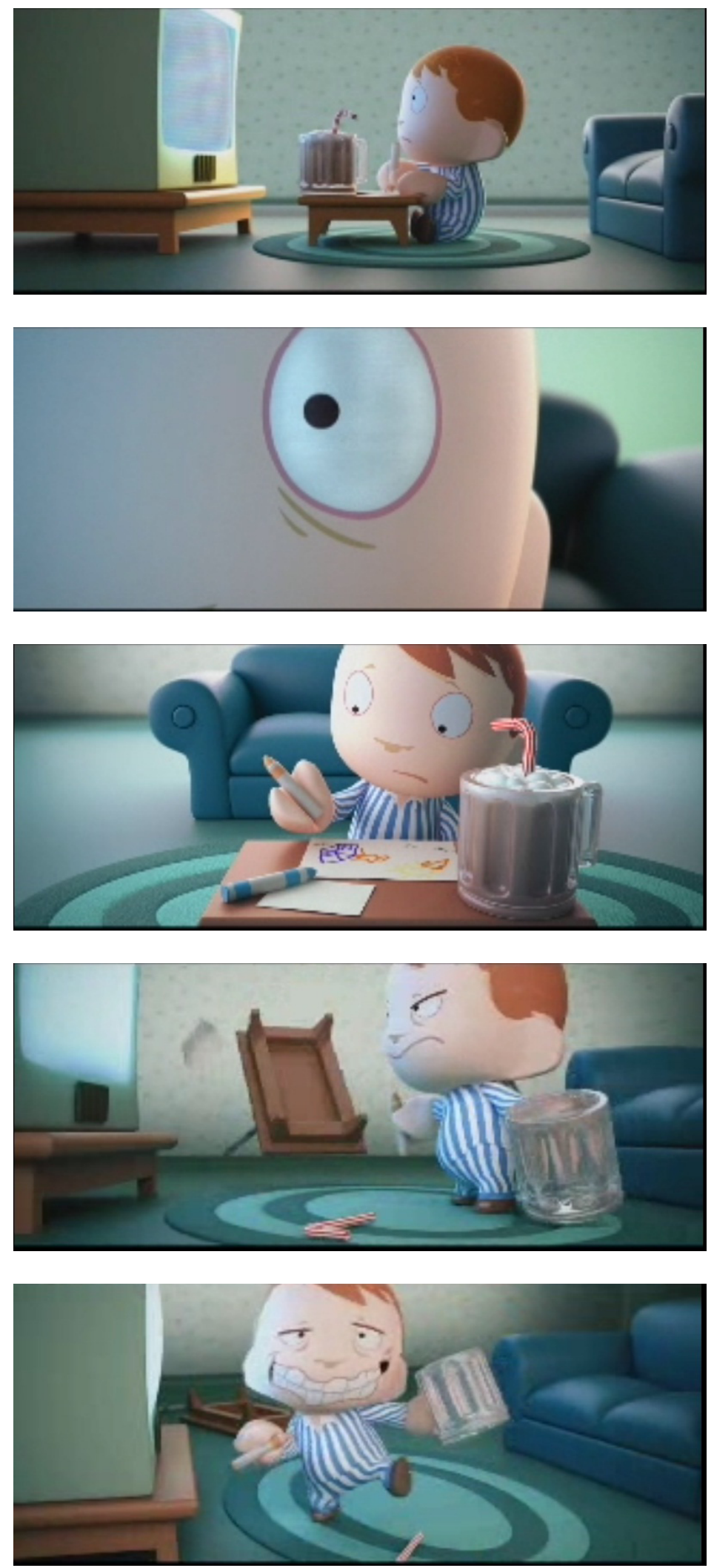

Imagens 5 a 9. Frames selecionados do vídeo Drogas, parte da campanha Não se engane: tem coisas que seu filho não está preparado pra ver, do Ministério da Justiça ${ }^{8}$. 
O vídeo mostra uma criança assistindo televisão enquanto desenha. Ela interrompe sua atividade para ver algo na tela - que não é vislumbrado, pois só se vê o reflexo distorcido da tela no seu olhar - até que a criança pega seu lápis de colorir e o coloca na boca, como um cigarro, e toma sua caneca com um inofensivo achocolatado como se fosse uma bebida alcoólica. A seguir, também reproduz os efeitos dessa intoxicação imaginária, virando violentamente a mesa, cambaleando e rindo, mesclando expressões de ira, descontrole e prazer. Sem narração ou texto para acompanhar a trilha sonora infantil que decai ao final, acompanhando a mímica embriagada da criança, a sequência só é interrompida, próximo do final, para a leitura em off dos dizeres da campanha em um logo idêntico ao visto nos cartazes: "Não se engane: tem coisas que seu filho não está preparado para ver. Confira sempre a classificação indicativa. Ministério da Justiça. Governo Federal.".

Inicialmente, salta aos olhos como é irônica a intoxicação imaginária do personagem. Em primeiro lugar, um grau mais básico de mimetismo é implicado: a conduta seria mimetizada, levando a criança a imitar os gestos adultos do fumo e do consumo de bebidas alcoólicas. Além disso, a propaganda sugere também um grau mais elevado e inesperado: os efeitos dos abusos tóxicos também são percebidos. Assim como a criança, também o achocolatado e o giz de cera parecem ter sido contaminados ou intoxicados pelas substâncias químicas que devem ter encontrado alguma forma para transpor a tela da TV, embriagando a criança.

Obviamente, trata-se de uma hipérbole humorística, que não pretende sugerir seriamente que a mimetização das condutas pode simultaneamente causar a reprodução de seus efeitos ${ }^{9}$. Porém, o paralelismo atrai uma 
interpretação intrigante: não deixa de ser irônico o fato de que muitas das pesquisas que defendem o contágio midiático adotam o modelo hipodérmico, assim cunhado devido à interpretação de que o público poderia ser inoculado com mensagens - como agulhas hipodérmicas - e contagiado a adotar certas ideias ou comportamentos. Como bem lembra Citelli (2010, p. 75), "os fantasmas do funcionalismo e sua visão hipodérmica - o receptor reage imediatamente aos apelos do emissor - continuam à solta"10.

Também é interessante perceber como o termo confusão também encontra um eco nesse vídeo, visto que a criança confunde realidade com ficção da mesma forma como os críticos da classificação indicativa (a atual realidade desejada pelos propositores da campanha) a confundem com censura (vilã ficcional, na distinção já representada).

Talvez não cause estranhamento a ausência de pais ou responsáveis no sofá vazio ao fundo, mostrado rapidamente no vídeo - afinal o verdadeiro protetor e guardião da infância seria, nesse modelo, o Estado, que fala em nome do público e da ciência e alerta sobre o inadequado. Como defendido pelo artigo do ministro da justiça citado anteriormente, a classificação indicativa seria justificada por atender clamor público (incentivado também por essa campanha) e como resposta a pesquisas sobre a influência perniciosa da mídia: afinal, a classificação não se difere da censura justamente por sua abertura democrática a "consultas públicas e estudos especializados sobre o comportamento das crianças e sua tendência de imitar aquilo que assistem" (CARDOZO; ABRÃO, 2012)?

Essa tutela da opinião pública (PETLEY, 2007, p. 37) - em que o Estado assume o papel paternalista ao sugerir ou controlar o que considera

animado em que personagem animalizado bate com uma bigorna na cabeça de outro, que é amassado e, logo em seguida, volta a sua forma original" (MINISTÉRIO DA JUSIÇA, 2012, p. 9). Cabe refletir se a intoxicação imaginária do vídeo analisado também não receberia uma classificação igualmente branda. 
adequado para o público limitado - é criticada por autores desde Milton, e ressurge nessa campanha de forma reveladora: a propaganda baseia-se em um imaginário infantil para chocar o público sobre a dissonância etária entre imagens e temas, mas também pode ser lida como uma proposta de infantilização do seu próprio público.

\section{Conclusão}

Moscovici (2007, p. 96) já apontava como um senso comum reconstruído pode prestar-se ao serviço de uma "ideologia dominante" por meio de três fases: uma "fase científica", formulada por estudos e pesquisa em um campo do saber; uma "fase representativa", em que seus conceitos são difundidos socialmente para além das fronteiras dos especialistas, mas com sua ajuda; e por fim uma "fase ideológica", em que as representações sociais seriam apropriadas "por um partido, uma escola de pensamento ou um órgão do estado" (MOSCOVICI, 2007, p. 96). Claramente, esse também foi o percurso aqui tangenciado da construção das representações sociais atreladas à classificação indicativa: das análises de conteúdo e estudos behavioristas (AUMONT, 1993, p. 92), passando pela sua difusão por meio de organizações preocupadas com a formação dos jovens e as influências nocivas das mídias de massa (CITELLI, 2010), até ser abrigada, em alguns casos, dentro do aparato estatal como política pública de controle (MINISTÉRIO DA JUSTIÇA, 2012).

Adaptando a terminologia de Charaudeau sobre os "discursos circulantes" - soma de enunciados que definem "o que são os seres, as ações, os acontecimentos, suas características, seus comportamentos e os julgamentos a eles ligados" (CHARAUDEAU, 2006, p. 118) - é possível sugerir que estratégias de limitação comunicativa como a classificação indicativa propõem o controle sobre a circulação dos discursos. Em primeiro lugar, como arena de disputa, reforçam a instituição de campos de "poder/contra-poder" (p. 118) por envolver o conflito sobre quem tem a legitimidade para definir a correção das práticas 
e suas eventuais sanções. Em segundo lugar, obviamente também reforçam a "função de regulação do cotidiano social" (p. 119). Mas, além desses dois fatores já apontados por Charaudeau (2006), o debate sobre a classificação indicativa revela também uma tensão - ironicamente - sobre a indicação classificativa. Em outras palavras, o que está em disputa é o poder (classificativo) de determinar (pela indicação) os sentidos que devem ser considerados como legítimos para termos polêmicos como censura, constitucional, legal, apropriado, inadequado, buscando aplainar as irregularidades e as diferenças de concepção, apelando para sentidos que se impõem como consensuais - seja pela força ou pela argumentação, duas estratégias que se misturam em instâncias como o STF, que pondera, discute e apresenta suas conclusões, mas também apresenta força normativa e coercitiva.

Por fim, vale concluir que o termo censura continua a carregar um "estigma", nas palavras de Kushnir (2004, p. 130). Não é de surpreender que a autora avaliava o sentido indesejado da pecha censória na transição democrática dos finais dos anos 1980, quando a censura de filmes e programas televisivos representava um fardo deixado pelo período autoritário anterior que se pretendia superar. Na época, a solução adotada foi a troca da terminologia, abandonando o termo censura e adotando a supostamente neutra classificação que indicaria, "por faixa de idade e não mais simplesmente proibitiva" (SIMÕES, 1999, p. 246). Entretanto, o impasse no STF sugere que a definição dos limites sobre a limitação (ou seja, sobre o controle das sanções, questionadas como antidemocráticas) revela o desconforto de uma democracia recente ao lidar com o clamor por controle, vigilância e punições. Não é mais (se é que já foi) possível controlar os desvios comportamentais no que toca a violência, a sexualidade e o consumo de substâncias químicas. Cabe saber se é legítima (ou eficiente) a vingança simbólica contra suas representações, punindo os que ainda ousam mostrar aos jovens os sofrimentos e prazeres que eles precisarão saber enfrentar no futuro. 


\section{Referências}

AUMONT, J. A imagem. Campinas (SP): Papirus, 1993.

BADIOU, Alain. Pequeno manual de inestética. São Paulo: Estação Liberdade, 2002.

BARKER, Martin. Audiences and Receptions of Sexual Violence in Contemporary Cinema. London: British Board of Film Classification (BBFC), 2007. Disponível em: http://www. bbfc.co.uk/download/policy-and-research/Audiences\%20and\%20Receptions\%20 of\%20Sexual\%20Violence\%20in\%20Contemporary\%20Cinema.pdf

BOLTER, Jay David; GRUSING, Richard. Remediation: understanding new media. Massachusetts: MIT Press, 2000.

CARDOZO, José Eduardo; ABRÃO, Paulo. "A importância da classificação indicativa". Folha de São Paulo, 30/03/2012. Disponível em: http://www1.folha.uol.com.br/fsp/ opiniao/34210-a-importancia-da-classificacao-indicativa.shtml

CHARAUDEAU, Patrick. Discurso das mídias. São Paulo: Contexto, 2006.

CITELLI, Adilson. "Comunicação e educação: convergências educomunicativas". Comunicação, Mídia e Consumo, v. 7, n. 19, jul. 2010.

FIGUEIREDO, Vera Lucia Follain. Narrativas migrantes: literatura, roteiro e cinema. Rio de Janeiro: 7 letras; PUC-RJ, 2010.

HAMBURGER, Esther. "Políticas da representação: ficção e documentário em Ônibus 174". In: MOURÃO, Maria Dora; LABAKI, Amir. O Cinema do Real. São Paulo: Cosac Naify, 2005.

. "Violência e pobreza no cinema brasileiro recente: reflexões sobre a ideia de espetáculo". Novos Estudos CEBRAP, n. 78, julho 2007. Disponível em: http://www.scielo.br/scielo.php?script=sci_arttext\&pid=S0101-33002007000200011 [Acessado em 30 ago. 2012].

KUSHNIR, Beatriz. Cães de guarda: jornalistas e censores, do AI-5 à Constituição de 1988. São Paulo: Boitempo, 2004. 
LIMA, Luciana. "Classificação indicativa não pode ser confundida com censura, diz ministro da Justiça". Agência Brasil, 19/03/2012. Disponível em: http://agenciabrasil. ebc.com.br/noticia/2012-03-19/classificacao-indicativa-nao-pode-ser-confundida-comcensura-diz-ministro-da-justica

LYOTARD, Jean-François. "O acinema". In: RAMOS, Fernão Pessoa. Teoria contemporânea do cinema - volume I: pós-Estruturalismo e filosofia analítica. São Paulo: Editora Senac, 2005.

MINISTÉRIO DA JUSTIÇA, SECRETARIA NACIONAL DE JUSTIÇA, DEPARTAMENTO DE JUSTIÇA, CLASSIFICAÇÃO, TÍTULOS E QUALIFICAÇÃO. Manual da nova classificação indicativa. Brasília: Ministério da Justiça, 2006. Disponível em: www.mj.gov.br/classificacao

MINISTÉRIO DA JUSTIÇA, SECRETARIA NACIONAL DE JUSTIÇA, DEPARTAMENTO DE JUSTIÇA, CLASSIFICAÇÃO, TÍTUlos E QUALIFICAÇÃO. Classificação Indicativa: Guia Prático. 2a Ed. Brasília: Ministério da Justiça, 2012. Disponível em: www.mj.gov.br/classificacao

MOSCOVICI, Serge. Representações sociais: investigações em psicologia social. $5^{a}$ Ed. Petrópolis: Vozes, 2007.

PETLEY, Julian. Censoring the word. London / New York / Calcuta: Seagull, 2007.

PRETZEL, Bruna Romano. O ministro Marco Aurélio e a liberdade de expressão. São Paulo: Sociedade Brasileira de Direito Público (SBDP), 2008. Disponível em: http:// sbdp.org.br/arquivos/monografia/93_Bruna\%20Romano\%20Pretzel.pdf

RANCIÈRE, Jacques. A partilha do sensível: estética e política. São Paulo: Ed.34, 2005.

RYAN, Marie-Laurie. Narrative across media: the languages of storytelling. Nebraska: Univ. Nebraska Press, 2004.

SIMÕES, Inimá. Roteiro da intolerância: a censura cinematográfica no Brasil. São Paulo: Senac, 1999.

WHITE, Hayden. Trópicos do discurso: ensaios sobre a crítica da cultura. 2a Ed. São Paulo: Edusp, 2001. 